\title{
Uma casa para "todo tipo de gente": a população em situação de rua e as formas de habitar um espaço liminar
}

\author{
Ericleuson Cruz de Araujo ${ }^{1}$ \\ Vanderlan Silva ${ }^{2}$ \\ Universidade Federal de Campina Grande
}

Resumo: O artigo apresenta a narrativa de um Centro de Referência Especializado para a População em Situação de Rua - Centro POP, através de descrições etnográficas realizadas a partir de observações no lugar que foi pensado para ser uma casa destinada a essa população. A instituição tem o objetivo de organizar a vida social dos assistidos em um espaço físico, por um período determinado, para que transitem da situação de rua ao modelo convencional de vida adotado, proposto e autorizado por uma Política Pública. Em contraponto à dicotomia entre o público e o privado, representados pela rua e a casa, o Centro POP constitui as suas próprias formas de habitar, utilizado como unidade de análise que permite atribuir à experiência na instituição categorias como a da liminaridade.

Palavras-chave: Centro POP; população em situação de rua; usuários; communitas.

\footnotetext{
${ }^{1}$ Graduado em Direito pela Universidade Estadual da Paraíba. Mestrando vinculado ao Programa de Pós-graduação em Ciências Sociais da Universidade Federal de Campina Grande. Integrante do Grupo de Pesquisa SOCIATOS - Sociabilidades e Conflitos Contemporâneos (CNPq/UFCG).

2 Professor de Antropologia da UFCG e docente do Programa de Pós-graduação em Ciências Sociais da mesma universidade. Doutor em Ciências Sociais pela Universidade Paris V (Sorbonne). Líder do Grupo de Pesquisa SOCIATOS - Sociabilidades e Conflitos Contemporâneos (CNPq/UFCG).
} 


\title{
A house for "all kind of people": the street population and the ways to live a limitary space
}

\begin{abstract}
The article presents the narrative of a Specialized Reference Center for the Homeless Population - POP Center, through ethnographic descriptions made from observations in the place that was thought to be a house for this population. The institution has the objective of organizing the social life of the assisted in a physical space, for a determined period, so that they move from the street situation to the conventional model of life adopted, proposed and authorized by a Public Policy. In contrast to the dichotomy between the public and the private, represented by the street and the house, the POP Center constitutes its own ways of living, used as a unit of analysis that allows categories such as liminality to be attributed to experience in the institution.
\end{abstract}

Keywords: POP Center; Homeless population; Users; communitas.

\section{Una casa para "todo tipo de personas": la población callejera y las formas de vivir un espacio liminar}

\begin{abstract}
Resumen: El artículo presenta la narrativa de un Centro de Referencia Especializado para la Población Sin Hogar - POP, a través de descripciones etnográficas realizadas a partir de observaciones en el lugar que se pensaba era el hogar de esta población. La institución tiene como objetivo organizar la vida social de los asistidos en un espacio físico, durante un tiempo determinado, para que pasen de la situación de calle al modelo de vida convencional adoptado, propuesto y autorizado por las Políticas Públicas. En contraste con la dicotomía entre lo público y lo privado, representada por la calle y la casa, el Centro POP es una forma de vida propia, utilizada como una unidad de análisis que permite atribuir categorías como la liminalidad a la experiencia de la institución.
\end{abstract}

Palabras clave: Centro POP; población en situación de la calle; usuarios; communitas. 
$\mathrm{E}$ ste artigo é resultado de pesquisa realizada junto à população em situação de rua na cidade de Campina Grande-PB, especialmente dos indivíduos que frequentam o Centro POP, destinado pela prefeitura da cidade para acolher os moradores que ali desejam estar. Tais frequentadores são tratados como "usuários" pelos servidores do ente estatal. A estadia na casa implica em um conjunto de procedimentos burocráticos de observância obrigatória pelo "usuário", que o coloca no seio de novas teias relacionais estabelecidas com os servidores do Centro POP, bem como entre os "usuários". A análise dessas relações constitui o objetivo do presente artigo.

Muitos estudos antropológicos têm possibilitado analisar a dinâmica da vida em sociedade e suas dicotomias a partir de múltiplas perspectivas. E, uma das possibilidades mais instigantes tem sido, sem dúvida, observar as relações estabelecidas por grupos e indivíduos que se situam ou que com frequência estão nas franjas da vida social. Tal possibilidade, aqui abraçada, nos ajuda na compreensão das relações estabelecidas pelos interlocutores dentro do universo social indicado.

Na busca de compreender os olhares e práticas dos "descontentes" e "marginalizados", autores como Goffman (1985) e Turner (1969-1987) são importantes para nos ajudar a perceber o olhar distanciado, elaborado a partir das margens, pois nelas a sociedade costuma mostrar o seu inacabamento, ajudando a produzir olhares e práticas a partir dos "resíduos", "rejeitos" sociais, das rupturas, "das interrupções e das coisas não resolvidas da vida social” (DAWSEY, 2005: 29).

Os moradores em situação de rua atendidos pelo Centro POP na cidade paraibana são pessoas que se encontram em posições de liminaridade, na medida em que se veem desprovidos do aconchego da casa familiar e do convívio cotidiano com parentes. Nas sociedades ocidentais, indivíduos que não seguem pressupostos tidos como convencionais surgem aos olhos da maioria estabelecida como marginalizados, rejeitados, fontes de perigo. Para os que se encontram em situação de rua equivale a não ter lugar fixo de moradia, em inúmeros casos isso implica em ter vínculos profissionais rompidos; não ter certeza de quando poderá fazer a próxima refeição nem sobre o que irá comer. Viver nas ruas das cidades brasileiras talvez seja uma das situações sociais que mais revelam inconsistências sociais produzidas em nosso país, com todas as possíveis consequências que se apresentam para os que no dia a dia reconstroem suas referências para além das ruas e das casas nas quais os moradores estabelecidos e controlados pela lógica burguesa da localização podem ser encontrados.

Refletindo sobre sua relação com os indianos do Himalaia durante a pesquisa de campo, Berreman destaca o "não-lugar" por ele ocupado inicialmente naquele universo cultural, fazendo com que os aldeões tivessem dificuldade de situá-lo e portanto, de controlá-lo. O olhar que predomina em nossa sociedade em relação aos moradores em situação de rua se assemelha aquele dos moradores do Himalaia em relação ao pesquisador. Os que se encontram em situação de rua são vistos como estrangeiros, não vindos de longe, mas surgidos das próprias entranhas da sociedade a qual todos que o veem e lhe classificam, pertencem igualmente, mesmo que ocupando lugares distintos. E por isso ele, o estrangeiro é observado 
e temido como fonte de perigo, pois "a única maneira de garantir que esses perigos não são inerentes a uma pessoa é saber quem ela é, e para sabê-lo, ela deve ajustar-se em algum lugar no sistema social conhecido" (BERREMAN, 1975: 123).

$\mathrm{O}$ fato de estar fora daquilo que parece constituir elemento basilar de nossa sociedade, a residência privada, faz com que os moradores em situação de rua sejam vistos como desajustados, rejeitados e temidos em nossa sociedade. Nas análises apresentadas por Roberto DaMatta (1997), ele propõe pensar a sociedade brasileira a partir da dicotomia entre o espaço da casa e o da rua, situando o primeiro como lugar do aconchego e da intimidade, ao passo que a rua é apresentada como lugar público, espaço marcado pela impessoalidade e pela predominância de regras que se baseiam na racionalidade. Mesmo reconhecendo que tal dicotomia está presente na sociedade brasileira, atentamos para o fato de que tais lugares não são "puros", imunes a outras possibilidades relacionais que vão além daquelas idealizadas, recorrentes e desejadas em cada um desses lugares. Portanto, o espaço da casa também pode ser o lugar no qual os conflitos emergem e onde muitas vezes a ruptura relacional entre parentes se impõe, sendo uma das causas da "produção" de situações de moradia na rua, não a única, evidentemente.

Muitos dos trabalhos acadêmicos produzidos sobre moradores em situação de rua se voltam para os estudos das políticas públicas, da assistência social ou dos direitos humanos, como afirma Sposati (1995), e, embora seja inquestionável o valor de tais análises, nosso estudo se afasta de tal perspectiva, para se centrar em análises antropológicas que buscam evidenciar as configurações relacionais estabelecidas por moradores em situação de rua, particularmente dos que frequentam o Centro de referência POP na cidade de Campina Grande.

O Centro POP é resultado de intervenção federal para prestar assistência à população em situação de rua, que tradicionalmente tem sido atendida por instituições filantrópicas, muitas das quais ligadas a grupos religiosos. No Centro os indivíduos que aceitam se beneficiar dos serviços assistenciais oferecidos passam a ter acesso a uma casa e ao que dela se espera, provisoriamente, deixando para trás a condição de rua para ocupar a de "usuários” dessa unidade.

\section{O Centro POP: a casa, o extraordinário e a liminaridade}

No ano de 2009 foi instituída a Política Nacional para a População em Situação de Rua, que, como o próprio nome sugere, trata-se de política pública voltada para atender pessoas que se encontrem em situação de rua. Para tanto, foram criados os Centros de Referência Especializados (Centro POP), que é uma unidade prestadora de serviços assistenciais, que visa atender indivíduos que aceitem os serviços oferecidos pelo Centro, entre eles a disponibilidade de moradia, através da qual poderão superar, mesmo que provisoriamente, as condições encontradas na rua, passando a ser, a partir de então, "usuários" do centro.

Instituída pelo Decreto 7.053/o9, tal política pública define a população em situação de rua e, portanto, os potenciais “usuários” como sendo

\footnotetext{
o grupo populacional heterogêneo que possui em comum a pobreza extrema, os vínculos familiares interrompidos ou fragilizados e a inexistência de moradia convencional regular, e que utiliza os logradouros públicos e as áreas degradadas como espaço de moradia e de sustento, de forma temporária ou permanente, bem como as unidades de acolhimento para pernoite temporário ou como moradia provisória.
}

Desde que a definição oficial trazida pela lei delineia as principais características a partir das quais os Centros de acolhimento estabelecem os critérios para 
recepcionar e aceitar como "usuários" as pessoas que o procuram. Nossos primeiros contatos com o Centro POP na cidade de Campina Grande ocorreram no ano de 2017. Quando então realizamos as primeiras incursões etnográficas com o objetivo de nos familiarizarmos com o cotidiano dos "usuários" naquela instituição. Naquele ano, o Centro havia sido recentemente instalado na cidade. As primeiras observações realizadas sobre a unidade institucional nos fizeram observar que o modelo arquitetônico da edificação não se diferencia das demais habitações familiares da rua na qual está situado. A casa onde funciona o Centro foi alugada pela prefeitura da cidade para tal finalidade e algumas reformas foram executadas para se adequar aos usos a serem feitos. Ao nos aproximarmos da casa percebemos a presença de elementos que destoam de outras edificações no entorno, tais como a presença de Câmeras de segurança, cadeado fechado no portão e um segurança controlando a entrada e a saída das pessoas.

Em seu interior temos a certeza da diferença em relação as outras casas da rua, pois a presença de placas sinalizando e orientando a direção de cada ambiente indicam a relação de impessoalidade e de ausência de intimidade de quem chega ao lugar. No cômodo de entrada da casa fica a sala de triagem, onde é feito o atendimento e cadastro dos que chegam na condição de "usuários". Ao lado da triagem se situa a coordenação, que ostenta em sua porta uma placa informativa, que indica a exclusividade de acesso aos funcionários do Centro. Tal delimitação indica, de maneira clara quem pode ter acesso aos bastidores da instituição e quem deve ficar restrito aos espaços de uso coletivo. Na sequência tem-se a sala de atendimentos psicológico e jurídico. O refeitório vem na sequência, uma sala ampla, com mesas e cadeiras. Após o refeitório temos os alojamentos no qual os "usuários" dormem.

Nas primeiras conversas com a coordenadora, ela fez questão de ressaltar que todas as pessoas assistidas na casa eram usuárias e que tal tratamento é uma determinação da lei que institui a Política Nacional para a População em situação de rua. Segundo a diretora, independentemente das origens das pessoas e das histórias que contavam sobre como se tornaram moradores em situação de rua, uma vez elas aceitavam ir para o Centro POP, isso implicaria que ali elas deviam ser tratadas como usuárias da casa.

Certamente, tal "aceitação" não é desprovida de resistências nem de conflitos por partes dos "usuários”. Essa nova categorização não é capaz de suplantar as histórias pretéritas nem as marcas deixadas dos que ali chegam em busca de acolhimento, de comida e de uma cama para dormir. A impessoalidade presente na maior parte dos tratamentos dispensados pelos funcionários aos "usuários", bem como a situação de provisoriedade sentida pelos acolhidos faz com que se sintam em situações de liminaridade, pois se veem fora da rua, mas igualmente distantes do aconchego familiar que a casa tradicional representa.

Talvez nós pudéssemos pensar as relações estabelecidas pelos "usuários" do Centro POP aqui, indicado a partir da sociologia do desvio, identificando os indivíduos em situação de rua como "outsiders", por assumirem comportamentos divergentes daqueles tidos como normais, para lembrar a classificação defendida por Becker (2008). Poderíamos ainda fazer uso de análise que se voltasse para pensar a situação de carência dos meios necessários para a sobrevivência dos indivíduos como um fomentador das deteriorações, representados como "população excedente" numa sociedade na qual poucos ocupam as posições mais altas na escala piramidal, conforme os estudos de Bauman (2005). Mesmo reconhecendo o valor e as importantes contribuições trazidas por tais análises, nós optamos por uma perspectiva teórica que nos permitirá analisar as situações de liminaridade 
nas quais as pessoas em situação de rua acolhidas no centro POP se encontram. Nesse sentido, os estudos desenvolvidos por Victor Turner $(1974 ; 1982 ; 1987)$ na sociedade Ndembu são inspiradores. Os estudos empreendidos por Goffman (1985) também se mostram estimulantes, na medida em que o autor procura pensar a vida social a partir das análises microssociológicas.

Mesmo tendo clareza dos pontos divergentes entre tais perspectivas teóricas, a proposta é trabalhar com os conceitos e categorias da antropologia do processo ritual, de Turner, dentro de um recorte em perspectiva contemporânea, concentrando os esforços em fazer as devidas contextualizações das abordagens, bem como com as contribuições de Goffman, desencadeando no que pode preceder estudo descritivo etnográfico ambientado no Centro POP.

Tal como Dawsey (2005) ao analisar o teatro dos "bóias-frias", procuraremos não abrir mão da conciliação entre os dois teóricos na análise dos "usuários" do Centro POP. O próprio Turner (1987) estabeleceu as diferenças entre a sua perspectiva e a de Goffman, no tocante à representação pelo teatro. Enquanto o sociólogo canadense se dedica ao teatro da vida cotidiana, com fachada e os seus demais elementos, Turner observa os momentos extraordinários da vida ou o metateatro da vida em sociedade.

Em "O Processo Ritual: estrutura e antiestrutura” Victor Turner (1974) dedicou seus estudos aos rituais, contribuindo significativamente para a interpretação das práticas rituais a partir da exploração da noção de liminaridade, em sequência das análises dos ritos de passagens elaborados por Arnold Van Gennep (1978), propondo nova categoria: o conceito de communitas. Em "Os Ritos de passagem", Van Gennep (1978), pensa tais ritos como estruturados em três tipos: 1) ritos de separação; 2) ritos de transição; e 3) ritos de reagregação. Nesse sentido, a estadia no Centro POP se apresenta como um rito de transição que situa as pessoas que lá são acolhidas entre o mundo da rua e o da casa. Portanto, nas palavras de Turner, eles vivem uma experiência de liminaridade.

$\mathrm{Na}$ análise dos ritos de iniciação ou puberdade dos neófitos do povo Ndembu como entidades liminares, na África Central, apesar de se referir claramente às relações estabelecidas no contexto estudado, em muito tal autor contribui para pensar o processo pelo qual passam as pessoas em situação de rua, ao se tornarem usuárias do Centro POP. Neste caso, o objetivo da política pública é transformar a realidade social dos indivíduos. Para tanto, tal como no processo ritual observado na sociedade Ndembu, a pessoa é conduzida a passar por fases, desde a triagem na primeira sala do centro, até se juntar aos outros "usuários", nos quartos para dormir por trás do portão gradeado. Mas mais do que isso, o Centro funciona como esse lugar de transição entre a rua que se vislumbra (se ilude?) tenha ficado para trás e a casa, a qual se poderá ser novamente conseguida (ou retornar?) no futuro.

A condição extraordinária da vida, representada pela situação de rua é eleita como um problema a ser enfrentado pelas diretrizes da política pública. A vulnerabilidade social tem sido pensada a partir de várias perspectivas teóricas como complexa, mas sua análise estaria intimamente ligada à carência de acesso aos meios materiais, produzida pela diferença entre a capacidade de produção e disponibilidade de aparatos para consumo. Assim, se produziriam as "deteriorações que desnivelam as condições objetivas para a competição social entre os indivíduos" (ABRAMOVAY, 2002: 192).

Por isso, o Estado, cumprindo com o suposto dever de manter a harmonização social que lhe é esperado, procura os meios para "ressocializar", no dizer da política, esses indivíduos. O primeiro passo é dar-lhes uma casa. Nesse ponto, é 
possível identificar uma contradição, a casa Centro POP, como descrita, ainda que queira ser uma casa, somente o é de longe. De perto não é uma casa convencional, como se propõe a ser. Além do mais, como ressalta DaMatta (1997), não se pode misturar o espaço da rua com o da casa sem criar alguma forma de grave confusão ou conflito, de modo que cada espaço é próprio, com suas formas singulares de sociabilidade. Tudo isso para demonstrar que as interações são peculiares às ruas e às casas convencionais, como também na casa que não é só casa: o Centro POP.

O Centro POP institui a sua forma de habitar frente a qual os "usuários" têm que se deparar com regras distintas daquelas que a plasticidade e a dureza das ruas ofereciam, mas ao mesmo tempo tais regras também são diferentes daqueles que os agora "usuários" tinham outrora em suas casas. Os "usuários", pessoas advindas dos múltiplos contextos urbanos das ruas, deparam-se com o ambiente milimetricamente pensado para ser uma casa. Em que pese a perspectiva institucional da política pública de ser uma alternativa para essa população, o centro POP busca cumprir seu papel estatal, delimitado pela lei que o institui, de ser espaço que visa reagrupar, reintegrar as pessoas em situação de rua ao ambiente da casa. Contudo, a perspectiva do Centro se constrói a partir de paradoxo, pois ele não é casa privada e, portanto, diferentemente das casas de família tradicionais, cujas relações de parentesco sanguíneo ou por afinidade estão na base da convivialidade mútua, o Centro estabelece sua "casa" a partir da junção de pessoas com trajetórias de vidas díspares, sem laços de parentesco entre si. Ao mesmo tempo, ele não é um espaço privado, mas público, estatal, no qual a impessoalidade assume lugar de destaque, daí a necessidade de indicar cada um dos cômodos do Centro com placas informativas, pois num lugar cuja rotatividade de usuários é intensa, as placas servem como orientação da localização para quem chega.

Diferentemente do que se passa nas casas tradicionais, onde os membros da família aprendem ao longo das interações os usos distintos dos espaços caseiros, no Centro POP os "usuários" não participam da elaboração de regras, nem podem frequentar todos os espaços. Ao contrário, quando ele é recepcionado na triagem, já tem acesso às regras que ditam os espaços aos quais poderá ter acesso e aqueles nos quais, evidentemente, sua presença não será permitida. O espaço dos quartos não é, necessariamente um espaço de intimidade, na qual a privacidade esteja assegurada, pois eles são compartilhados por vários "usuários", muitos dos quais dormem em camas tipo beliche.

O funcionamento do centro, a partir do conjunto de regras, faz com que ele se situe entre o que as pessoas em situações de rua encontravam lá fora e o que em tinham outrora, em princípio, em suas casas. Por isso que, inspirados em Turner (1974), nós pensamos o Centro como um lugar liminar. Entre os ndembus, no rito de investidura do Kanongesha, o elemento liminar se inicia com a construção de um pequeno abrigo, distante da aldeia principal, sendo esse nomeado de kafw ou kafwi, que é um termo ndembu derivado de ku-fwa, que significa "morrer", por ser esse espaço destinado à morte do chefe eleito para o seu estado de homem comum. No caso dos "usuários" do Centro POP, a passagem para o retorno à casa pode não necessariamente se configurar, tal como deseja a política pública, pois muitas variáveis contribuem para que tal possibilidade possa ou não se realizar no futuro. Assim, essa transformação de morador em situação de rua em "usuário" do Centro POP já lhe assegura, durante o tempo que ali permanece, a condição de viver sob os auspícios de regras comuns aquele universo. Em outras palavras, eles passam a viver num espaço de liminaridade. 
A Política Pública cria e institucionaliza esse espaço transicional. E o Centro passa a ser esse lugar da passagem, por não ser a rua, mas tampouco ser a casa, em especial se considerarmos que na casa estão presentes os elementos convencionais de uma sociedade estruturada e a rua se apresenta, nesse contexto, como a anti-estrutura. O Centro é uma espécie de limbo, cujas classificações são elaboradas de maneira a situar os que parecem se encontrar em situações de suspensão.

\begin{abstract}
para os indivíduos ou para os grupos, a vida social é um tipo de processo dialético que abrange a experiência sucessiva do alto e do baixo, de communitas e estrutura, homogeneidade e diferenciação, igualdade e desigualdade. A passagem de uma situação mais baixa para outra mais alta é feita através de um limbo de ausência de "status". Em tal processo, os opostos por assim dizer constituem-se uns aos outros e são mutuamente indispensáveis. (TURNER, 1969: 120)
\end{abstract}

É notória a expectativa de muitos "usuários" que a passagem pelo Centro possa transformar a vida deles. Igualmente é inegável que muitos dos que aceitam residir no Centro POP retornam às ruas pouco tempo depois de terem passado pela triagem.

Dito isso, é importante ressaltar que o ritual observado em uma sociedade tribal, no século XX, na África, por suas peculiaridades deve ser pensado com ressalvas quando esse nos serve de inspiração para refletir sobre as relações estabelecidas por grupos situados em uma urbe ocidental, tal como nesse caso espeć́fico dos "usuários" do Centro POP em Campina Grande. No ritual tribal, as fases são bem definidas. Entretanto, ainda que em um contexto diferente, é interessante pensar as relações ambientadas no Centro como processo, especial se considerarmos a ampla variação de histórias de vida que cada morador em situação de rua carrega ao adentrar o centro POP.

\title{
"Se deixar, eles montam em cima": os usuários constituídos em condições de uma communitas
}

Numa das entrevistas concedidas à pesquisa, uma das coordenadoras do Centro falava, com orgulho, da importância do Centro, que segundo a mesma acolhia "todo tipo de gente". Para ela, "recolher" as pessoas em situação de rua, realizando inclusive um trabalho de busca ativa, para ressocializá-las, através do encaminhamento das mesmas para os serviços assistenciais considerados necessários e cabíveis (tratamento de desintoxicação, tratamento psicológico, recuperação de vínculos familiares, educação profissional, cadastro em programas para vagas de empregos etc.), é um trabalho de grande envergadura social.

Indagada se o Centro atendia as necessidades dos "usuários", ela, se recolocando sobre a cadeira e aumentando o volume da voz, respondeu: "Sim, com toda certeza. O serviço prestado é negócio de cinema.”. Como se pode antever, o tom da fala da coordenadora oscilava, a depender de quem ele falava. Quando era para se referir aos servidores que conduziam as atividades no centro, o tom se elevava, o gestual com as mãos dava ênfase aos adjetivos de qualidade que eram distribuídos aos seus auxiliares. Contudo, quando se referia aos "usuários", deixava "escapar" no tom da fala e nas palavras que as relações ali estabelecidas eram conflituosas. Numa das ocasiões chegou a afirmar: "Se deixar, eles montam em cima." Em algumas situações por nós testemunhadas, ela elevou o tom da voz para impor as ordens aos "usuários".

Muitos dos usuários se dizem satisfeitos com o apoio que recebem do Centro POP. As necessidades gerais, como moradia e alimentação suprem as necessidades básicas de todos, como eles mesmos nos relataram. Todavia, há as demandas 
individuais relacionadas às condições particulares dos “usuários". Em alguns dos casos que pudemos acompanhar, havia demandas particulares de pessoas idosas e de senhoras grávidas, por exemplo, que precisam de atenção e de cuidados especiais e que o Centro não conseguia providenciar com a mesma urgência observada no atendimento das necessidades gerais e cotidianas.

A sensação de passagem vivida no Centro está presente nas reflexões dos "usuários". Tal situação cria estabilidade no presente e insegurança em relação ao futuro. Numa das conversas com interlocutores, um deles asseverou: "Aqui é bom, mas não serve, não.”. A frase proferida pelo interlocutor afirma o reconhecimento das vantagens de estar no Centro, pois ali ele encontra apoio e por isso ali é apontado como "bom". Ao mesmo tempo, o Centro é indicado como um lugar que "não serve". No contexto do diálogo, nosso interlocutor frisa a situação de liminaridade da passagem pelo Centro POP, destacando que após sua saída, ele provavelmente retornaria às ruas da cidade, pois embora tenha parentes que residam na urbe, os laços estão rompidos, segundo ele em razão dos familiares não aceitarem a forma como ele faz uso de entorpecentes.

Estar no Centro POP enquanto usuário equivale a enfrentar situação ritual de passagem, frente à qual a observância de regras se mostra necessária para permanência, mesmo que as resistências e escapadas também sejam praticadas. No caso desse "usuário", em particular, usuário contumaz de drogas ilícitas, a exigência do Centro de permanecer "limpo" durante a estadia é uma regra pesada e difícil de ser seguida. Para se manter em estado de abstinência e assim poder permanecer no Centro, ele é obrigado a frequentar o serviço público de saúde especializado.

As ações do Centro POP se propõem a oferecer proteção e abrigo à população em situação de rua, isso implica, por conseguinte, na imposição de regras a serem seguidas por esses. E, subordinar-se a tais regras é se dispor a obedecer seus guardiões, os servidores e a direção do Centro POP. A classificação homogeneizadora atribuída pelo corpo dirigente às pessoas em situação de rua que chegam ao Centro, classificando-as como usuárias, tende a reconhecer as trajetórias de cada pessoa como negativa, razão pela qual elas "caíram" ali, solicitando apoio. Nesse sentido, tais experiência pretéritas não devem ser relembradas, valorizadas, a não ser para reforçar a necessidade de superação. O corpo dirigente sabe bem qual o papel que lhe cabe na instituição e, por conseguinte, o que deve ser seguido pelos "usuários". Ser atento à obediência das regras é uma maneira de evitar que os "usuários" "montem em cima". Em outras palavras, a diretora revela quem deve montar, quem deve impor as regras e dirigir os destinos daqueles que são tidos como levando suas "vidas ao léu".

Exercer o controle é uma maneira de assegurar a homogeneidade entre os "usuários" do Centro POP, mesmo que tal indiferenciação sirva, sobretudo, para o exercício burocrático e administrativo, para que o ente estatal não perca o controle sobre os outrora "rejeitados", "desestruturados":

\footnotetext{
É como se houvesse neste caso dois "modelos" principais de correlacionamento humano justapostos e alternantes. O primeiro é o da sociedade tomada como um sistema estruturado, diferenciado e frequentemente hierárquico de posições político-jurídicoeconômicas, com muitos tipos de avaliação, separando os homens de acordo com as noções de "mais" ou de "menos". O segundo, que surge de maneira evidente no período liminar, é o da sociedade considerada como "communitas", não-estruturado, ou rudimentarmente estruturado e relativamente indiferenciado, uma comunidade, ou mesmo comunhão, de indivíduos iguais que se submetem em conjunto à autoridade geral dos anciãos rituais. (TURNER, 1974: 118-119)
} 
Claramente, os "usuários" se assemelham nas particularidades de suas vidas e trajetórias. Paradoxalmente, é na diferença que residem suas semelhanças. Ainda assim, a fala da diretora e a categoria "usuário", criada pela política pública busca compreendê-los/classificá-los como iguais, homogêneos. O conceito de communitas de Turner nos ajuda a refletir sua as relações e classificações estabelecidas no Centro POP. Nele, a porta de entrada, o momento da acolhida vivenciado na sala de triagem, o primeiro banho, a refeição, a apresentação do lugar para dormir, o encontro com outros "usuários", a obediência e submissão à coordenação, às regras, a igualdade etc., são mais do que espaços singulares, eles delimitam possibilidades. As interações se dão nesse "limbo ou limiar entre o passado e o futuro estrutural" (TURNER, 2005: 183).

Mas, apesar de limiar, o Centro POP não é um vácuo. Ao contrário, ele busca produzir efeitos nas vidas das pessoas em situação de rua e o primeiro deles é ensinar a como ser "usuário". Quando da chegada de uma pessoa ao Centro as regras lhes são apresentadas. Nesse momento, a pessoa é colocada em uma posição verticalmente inferior aquele que ensina (diretora, funcionária), para aprender algo, numa relação similar ao processo de aprendizagem na escola infantil, com a presença de quadros de avisos, de imagens lúdicas ensinando onde jogar o lixo ou para que a descarga seja acionada ao se utilizar o banheiro. As regras são ditas e explicadas pedagogicamente pelos "educadores sociais".

O que acontece no Centro POP nesses momentos iniciais se assemelha ao que se passa nas prisões, tal como demonstrado por Goffman (1992) quando a instituição prisional explicita os deveres do novo interno e o isola por alguns dias, para assim fazer recair sobre seu corpo e sobre seu "espírito" a força das regras e pra que ele fique ciente a quem deve obedecer. Tal semelhança não se produz por acaso, pois a figura de educador social, prevista pela lei que criou o Centro POP em muito se assemelha à figura do agente penitenciário, cujo objetivo também se constrói a partir das responsabilidades de vigiar, punir e facilitar as ressocializações dos internos. No fundo, o Centro POP é resultado desse processo de refinamento, de suavização das penas e do maior e melhor controle sobre as vidas dos indivíduos que com suas ações se mostram como ameaças à ordem social, tal como já analisado por Foucault, Elias e Adorno.

\section{Considerações finais}

Pelas observações feitas no Centro POP, é possível perceber que a vida social dos moradores passa a ser organizada dentro dos limites físicos do prédio da unidade, influenciando no conjunto de interações, seja na divisão dos espaços, nas regras estabelecidas, no aprender a ser "usuário" e na performatização desse novo papel transitório a ser desempenhado, onde são manifestadas formas múltiplas e próprias de habitar.

$\mathrm{Na}$ unidade, a "casa" demonstra possíveis contradições da vida cotidiana. Ainda que tenha a pretensão de ser uma casa, o Centro POP se apresenta um espaço destinado à transição entre papeis sociais desempenhados pelos atores sociais que ele recebe na condição de "usuários", orbitando entre estrutura e antiestrutura, entre a rua e a casa convencional. Mas o Centro Pop não é nem a casa nem a rua. Ele é um limem, com status, com pretensão de ser, de estar e de existir em função da transição, ou transformação em um novo ser. Ele busca produzir transformações.

A finalidade da política pública é a mudança da realidade social dos indivíduos por ela assistidos. Para tanto, aos indivíduos em situação de rua que cruzam 
o portão de entrada do Centro POP é proposto um conjunto de regras, o desempenho de um novo papel, o de "usuário". Um papel que não permite muitas criações ou inovações, dadas às regras às quais ele estará a partir de então submetido, embora não impeça a emergência de formas de resistência. Como grupo "homogêneo", de iguais, os "usuários" acabam se organizando e fazendo surgir o que Victor Turner propõe pensar como uma communitas.

As representações no espaço liminar da unidade de que tal ambiente funcione como casa, e, por conseguinte pela imposição de regras que ditam as relações estabelecidas em seu interior, de modo que tais comportamentos individuais e as interações com outros indivíduos possam ser "ensaios" para que, no melhor dos casos, os que ali vivem possam pavimentar o futuro de suas vidas de "usuários". Em outras palavras, espera-se que o tempo de transição, a liminaridade vivida no Centro POP funcione como período de readaptação, de ressocialização que permita aos "usuários" se distanciarem das experiências e condições encontradas outrora nas ruas.

Por trás do arranjo elaborado pela Política Pública, as observações realizadas no Centro POP nos permitiram analisar o percurso percorrido pelos "moradores" que chegam para se estabelecer provisoriamente. A Política Pública, desse modo, ao mesmo tempo em que apresenta alternativa à situação de rua, limita as possibilidades disponíveis no contexto urbano para essa população, fazendo com que a promessa de retorno à vida convencionalmente organizada numa casa tradicional seja o principal objetivo a ser perseguido.

Ao acolher os "usuários" nesse ambiente de transição, o Centro POP oferece algumas condições que se assemelham àquelas presentes nas casas tradicionais $\mathrm{e}$ particulares das famílias, tais como acesso à alimentação, banho, cama, entre outras. Ao mesmo tempo, a partir da entrada no Centro os "usuários" passam a ter suas vidas formalmente administradas pelos dirigentes da instituição estatal e limitadas ao seu espaço físico institucional, o que sem dúvida se mostra como negação da autonomia que cada morador possivelmente exerceria em suas casas tradicionais. E isso não ocorre por acaso, pois enquanto espaço liminar o Centro POP se situa entre as ruas e os espaços privados, sem ser nenhum nem outro. E, embora sendo espaço de transição, ele não é um não-lugar, ao contrário, ele é um lugar no sentido antropológico, tal como pensado por Marc Augé (1994) e exatamente por ser um lugar ele é capaz de criar suas regras, assim como seus próprios personagens.

Recebido em 21 de setembro de 2020.

Aceito em 5 de dezembro de 2020.

\section{Referências}

ABRAMOVAY, Miriam et alli. Juventude, violência e vulnerabilidade social na América Latina: desafios para políticas públicas. Brasília: UNESCO, BID, 2002. 
AUGÉ, Marc. Não Lugares: Introdução a uma Antropologia da Supermodernidade. São Paulo: Papirus, 1994.

BAUMAN, Zygmunt. Vidas desperdiçadas. Tradução: Carlos Aberto Medeiros. Rio de Janeiro: Jorge Zahar, 2005.

BECKER, H.S. Outsiders. Estudos de sociologia do desvio. Rio de Janeiro: Jorge Zahar, 2008.

BERREMAN, Gerard. "Etnografia e controle de impressões em uma aldeia do Himalaia”. In: ZALUAR, Alba (org.). Desvendando Máscaras Sociais. Rio de Janeiro: Francisco Alves, 1975. pp. 123-174.

BRASIL. Decreto 7.053 de 23 de dezembro de 2009. Institui a Política Nacional para a População em Situação de Rua e seu Comitê Intersetorial de Acompanhamento e Monitoramento, e dá outras providências. Diário Oficial da União, Brasília, DF, 24 dez 2009. Disponível em: < http://www.planalto.gov.br/ccivil_03/_Ato2007-2010/2009/Decreto/D7053.htm>. Acesso em 28 jul. 2020.

CLIFFORD, James. A experiência etnográfica: antropologia e literatura no século XX. Rio de Janeiro: Editora da UFRJ, 1998.

DAMATTA, Roberto. A casa e a rua: espaço, cidadania, mulher e morte no Brasil. Rio de Janeiro: Rocco, 1997.

DAWSEY, J. C. 2005. O Teatro dos 'Bóias-frias': repensando a antropologia da performance. Horizontes antropológicos, 11 (24): 15-34, 2005.

GOFFMAN, Erving. A representação do Eu na vida cotidiana. Petrópolis: Vozes, [1959] 1985.

GOFFMAN, Erving. Manicômios, prisões e conventos. São Paulo: Editora Perspectiva, 1992.

MORAES, M. V. M. A construção de uma infância em uma escola pública de educação infantil da cidade de São Paulo. Dissertação de Mestrado, Antropologia, USP, 2012.

SILVA, Vanderlan. "Fazendo etnografia em campo minado: reflexões sobre os desafios da pesquisa antropológica em situações de risco". In: SILVA, Vanderlan (org.). Campos e Fronteiras Etnográficas nas Pesquisas em Escolas e Prisões. Campina Grande-PB: EDUFCG, 2017. pp. 45-65.

SILVA, Vanderlan. Conflitos e violências no universo penitenciário brasileiro. Porto Alegre: Sulina, 2008.

SPOSATI, Aldaiza de Oliveira. Assistência na Trajetória das Políticas Sociais Brasileiras: uma questão em análise. São Paulo: Cortez, 1995.

TURNER, Victor. O Processo Ritual: estrutura e anti-estrutura. Petrópolis: Vozes, [1969] 1974.

TURNER, Victor. Floresta de símbolos. Niterói: EdUFF, 2005.

TURNER, Victor. The Anthropology of performance. New York: PAJ Publications, 1987.

VAN GENNEP, Arnold. Os ritos de passagem. Petrópolis: Vozes, 1978. 